\title{
País Tropical e seu mimetismo: o discurso ufanista asso- ciado a Wilson Simonal e a desinvenção tropicalista*
}

\author{
Renan Paiva Chaves ${ }^{1}$ \\ Universidade de Campinas
}

Tendo-se como premissa a saliente capacidade mimética que têm as canções de Jorge Ben Jor, é analisada nesse artigo a música País Tropical, de sua autoria, em duas distintas versões, a de Wilson Simonal e a da Tropicália, ambas de 1969 , sob as quais busca-se verificar como ocorre o processo de reformulação do discurso, ufanista no primeiro e alegorizador do nacionalismo e dos produtos da indústria cultural no segundo. É notado, sobretudo, um trajeto de ressignificação que ultrapassa os limites da simples variabilidade interpretativa, inerente a qualquer objeto de análise, e que se caracteriza especialmente pela autenticidade com que a canção é transformada para o, e não apenas pelo, contexto.

Palavras-chave: Jorge Ben Jor Música - Tropicália - Wilson Simonal
Assuming the salient mimetic capacity of Jorge Ben Jor songs, this article analyzes one of his music: País Tropical. Two different versions are studied, one of Wilson Simonal and the other one of Tropicalism, both of 1969 , aiming at verifying the speech redraft process, patriotic in the first one and allegorizer of the nationalism and the products of cultural industry in the second one. It is remarkable, over all, a path of redefinition exceeding the simple interpretative variability, inherent to any object of analysis, but especially characterized by the authentic way the song is transformed to, and not just by, the context.

Keywords: Jorge Ben Jor - Music Tropicalia - Wilson Simonal.

\section{O artista trans-histórico e o mote}

$\mathrm{J}^{\mathrm{s}}$ orge Ben Jor, apesar do swing samba-jazz, do breve contato com a BossaNova, da aproximação à Jovem Guarda e do namoro com a Tropicália na década de 1960, sempre esteve, ao menos parcialmente, à margem dos movimentos musicais brasileiros (NASCIMENTO, 2005). Sua trajetória é marcada pela busca incessante de uma sonoridade única e indissociável de sua figura,

\footnotetext{
"País Tropical and its mimetism: the patriotic discourse of Wilson Simonal and the tropicalist desinvention ${ }^{1}$ Estudante de Música Popular do Departamento de Música do Instituto de Artes da UNICAMP. Endereço para correspondências: Rua Olyntho de Barros, 104, Bairro Residencial Burato, Campinas, SP, 13084-320 (piratarix@gmail.com).
} 
de caráter híbrido e original, influenciada enormemente pelas histórias em quadrinhos, das quais se aproveita dos mitos, das articulações entre a linguagem gráfica e verbal e da seqüencialidade temporal e também influenciada pelo futebol, a inspiração para a artimanha e malabarismo enquanto cancionista, de juntar texto e melodia (TATIT, 2002).

Jorge é, na definição concisa de Caetano Veloso (1997), um homem que habita um país utópico trans-histórico, idéia que elucida a facilidade com que transita e é aceito por diferentes movimentos e tendências musicais. Estendendo-se essa visão do artista a suas composições, pode-se inferir sobre a transversalidade que suas criações operam ao longo das várias épocas históricas e sobre as diferentes definições que uma mesma configuração discursiva ganha segundo os contextos em que aparece (LOPES, 1999). O que estaria em conformidade com a quantidade de artistas de diferentes seguimentos musicais, tanto em âmbitos mercadológicos quanto estéticos e políticos, que regravam suas canções: emblematicamente a música Mas Que Nada (1963), que alcançou, na interpretação de Sérgio Mendes, o topo da lista das canções mais tocadas nos Estados Unidos de acordo com o ranking da BillBoard, e que foi gravada por Elza Soares, Milton Nascimento, Luiz Eça, Bebeto, Paulinho Nogueira, Elis Regina, Leila Pinheiro, Maria Creuza, Tania Maria, Leo Gandelman, Nuno Mindelis, Ella Fitzgerald, Dizzie Gilespie, Julio Iglesias, Al Jarreau, Trini Lopez, José Feliciano, Fred Bongusto, Mina e Nicoletta.

Os sentidos diacrônicos, e mesmo os derivados dos elementos peculiares de cada arranjo e intérprete nas diversas regravações de composições de Jorge, podem ser frutos de sua capacidade mimética ${ }^{2}$ enquanto compositor. Capacidade que possivelmente está imbricada ao contexto de conturbação política e estética do início de sua carreira. Do qual soube, concomitantemente, participar e permanecer à margem sem rotulações, quando desejado: permeou a bipolarização ideológica da música popular brasileira dos anos 1960, protagonizada pelos participantes da Jovem Guarda e pelos compositores da Canção de Protesto; com o hibridismo das influências, metaforizado pelo violão e pela guitarra elétrica, conseguiu se posicionar entre o intimismo bossa-novista e a estridência tropicalista.

Partindo-se dessa premissa sobre a capacidade mimética das canções de Jorge Ben e com a finalidade de entender como ocorre o processo de reformulação discursiva, será feita a análise da versão de País Tropical gravada por Gal Costa (1969), na qual o discurso ufanista associado à gravação de Wilson Simonal (1969), cantor popularesco em vias de um comercialismo vulgar (VELOSO, 1997), é mimetizado pelo discurso tropicalista, marcadamente alegorizador do nacionalismo e dos produtos da indústria cultural (FAVARETTO, 2000).

\footnotetext{
${ }^{2}$ Entenda capacidade mimética como a potencialidade de se ajustar a novas situações, em um sentido mais atrelado a mimetismo (que remete a adaptação) do que a mimese (que remete a imitação).
} 


\section{O discurso ufanista}

Entre o golpe de 1964 - que representou um retrocesso político enorme, já que em épocas de Goulart o debate público centrava-se na reforma agrária, no imperialismo, no salário mínimo, no voto do analfabeto e nas organizações sindicais, operárias e rurais - e fins de 1968, apesar da ditadura da direita, havia relativa hegemonia cultural da esquerda no país, concentrada nos grupos produtores de ideologia, como os dos estudantes, artistas, jornalistas, sociólogos e economistas (SCHWARZ, 1978).

Todavia os acontecimentos políticos de 1968 - crescentes protestos e greves de trabalhadores, assaltos a bancos, manifestações públicas de repúdio ao governo militar, crescente confronto entre militares e estudantes e alguns acontecimentos salientes à opinião pública, como a explosão de uma bomba no consulado americano em São Paulo feita pela Aliança Libertadora Nacional (ALN), a "passeata dos cem mil" no Rio de Janeiro e o protesto de rua que resultou na morte do estudante Edson Luís (CALDAS, 2005) -, que alarmaram oficialmente a existência de uma guerra revolucionária, trouxeram mudanças drásticas ao ano que estava por vir.

A fim de evitar a popularização de uma suposta guerra revolucionária no Brasil, o silêncio ao debate político e cultural foi imposto pelo Ato Institucional número cinco (AI-5), que normatizou (1) a tortura, censura e exílio aos artistas e intelectuais transviados ao regime ditatorial, (2) a apropriação dos meios de comunicação de massa (em exponencial crescimento), em especial o da televisão, como veículos de manobra política e (3) a proliferação da propaganda ufanista do regime militar (NAPOLITANO, 2001). Entre o policialismo extremamente pesado, a tortura implacável, a repressão e a censura à imprensa e a profusão de bandeiras nacionais e de folhetos de propaganda renascia a ideologia do patriotismo ordeiro (SCHWARZ, 1978).

Nesse contexto, entre os decênios de 1968 e 1969, chegaria Wilson Simonal $^{3}$ a seu auge enquanto cantor (PINHEIRO, 2009), com as famosas interpretações de País Tropical (1969), Sá Marina (1968) e Meu Limão, Meu Limoeiro (1967): “1968 foi um ano terrível para Gil, Caetano e Chico,

\footnotetext{
${ }^{3}$ Simonal nasceu no Rio de Janeiro em 26 de fevereiro de 1939 em uma família pobre. Foi cabo do exército e costumava cantar nas festas e reuniões da companhia na qual serviu por três anos, $8^{\circ}$ grupo de Artilharia de Costa. Iniciou sua carreira cantando em bailes e em 1961 virou apresentador do programa "Os brotos comandam". Em 1963 gravou seu primeiro disco, e teve uma carreira ascendente até 1972, quando foi condenado por ser o mandante de uma tortura e acusado de ser informante do Dops. Sua carreira sofreu enorme declínio e apesar de continuar gravando alguns discos nas décadas de 1980 e 1990, não atingiu nenhum sucesso. Morreu em 25 de Julho/2000, no esquecimento midiático, de cirrose hepática.
} 
mas para Wilson Simonal e sua pilantragem ${ }^{4}$ foi triunfal, um hit atrás do outro, cada vez maiores" (MOTTA, 2000). Simonal "chegou a ser uma das pessoas mais famosas do Brasil, concorrendo com Roberto Carlos e abaixo apenas, talvez, de Pelé" (BOSCO, 2009).

A Shell, que seria a patrocinadora oficial da Seleção Brasileira de Futebol durante a copa do Mundo de 1970, investia vultosamente em Simonal, com a intenção de associar sua simpatia e popularidade à imagem da empresa e do Brasil, produzindo-o em numerosos shows, eventos, comerciais e programas de rádio e televisão. Simonal acabou por se projetar para além do nacional: fez turnês por toda a América Latina e Europa. Não havia álbum que não vendesse e show que o ingresso não se esgotasse (MOTTA, 2000).

Em paralelismo com a retomada da proliferação e da popularização da ideologia do patriotismo ordeiro, Simonal investiu sua carreira, não por desconhecimento, em diversas canções que faziam apologia ao regime militar, como País Tropical (1969), Brasil, eu fico (1970), Que cada um cumpra com o seu dever (1970), Resposta (1970), País do Futebol (1970) e Obrigado Pelé (1971) (FERREIRA, 2007). Sem a pretensão de esconder sua postura frente à produção musical na qual estava envolvido, revelou em uma entrevista ao jornal Pasquim (1969): "Não gravo disco para receber elogio, gravo disco para vender. Uso minha arte no sentido comercial". Simonal estereotipou-se e foi reconhecido e recebido pela crítica e pelos músicos como ícone da alienação e da postura pró-ditadura, sendo fortemente associado à imagem ufanista brasileira, proliferada pela ditadura militar.

Sob arranjo de César Mariano, em performance impecável e no irresistível balanço do grupo Som Três, Simonal conquistou as massas ao cantar País Tropical de Jorge Ben no álbum, pertencente a série Alegria, Alegria de quatro volumes, Homenagem à graça, à beleza, ao charme e ao veneno da mulher brasileira (1969) (Figura 1). Gravação que, potencialmente, se confunde em sentido semântico e musical com a postura e carreira de Simonal enquanto herói e símbolo das grandes massas.

Todavia, mesmo conquistando o Brasil, causou enorme polêmica, entrando em desacordo com o pensamento da esquerda intelectualizada:

No momento mais feroz da ditadura, em pleno terror, com tantas prisões e torturas, sob a mais truculenta censura, não se podia nem devia cantar o Brasil dos militares daquele jeito, com aquele amor ufanista. (MOTTA, 2000; p. 163).

\footnotetext{
${ }^{4}$ No texto Nascimento, Mudanças e Apogeu da Pilantragem de Carlos Imperial contido no encarte do LP Pilantrália - Carlos Imperial e a Turma da Pilantragem de 1968 resume que a idéia da pilantragem inicialmente estava atrelada a uma maneira mais "solta", dançante e swingada de se fazer arranjos e músicas, mas que em seguida se estendeu a uma filosofia de vida, que estaria traduzida na canção Nem Vem Que Não Tem de própria autoria e que estaria sintetizada na seguinte frase: "pilantragem é a apoteose da irresponsabilidade consciente".
} 


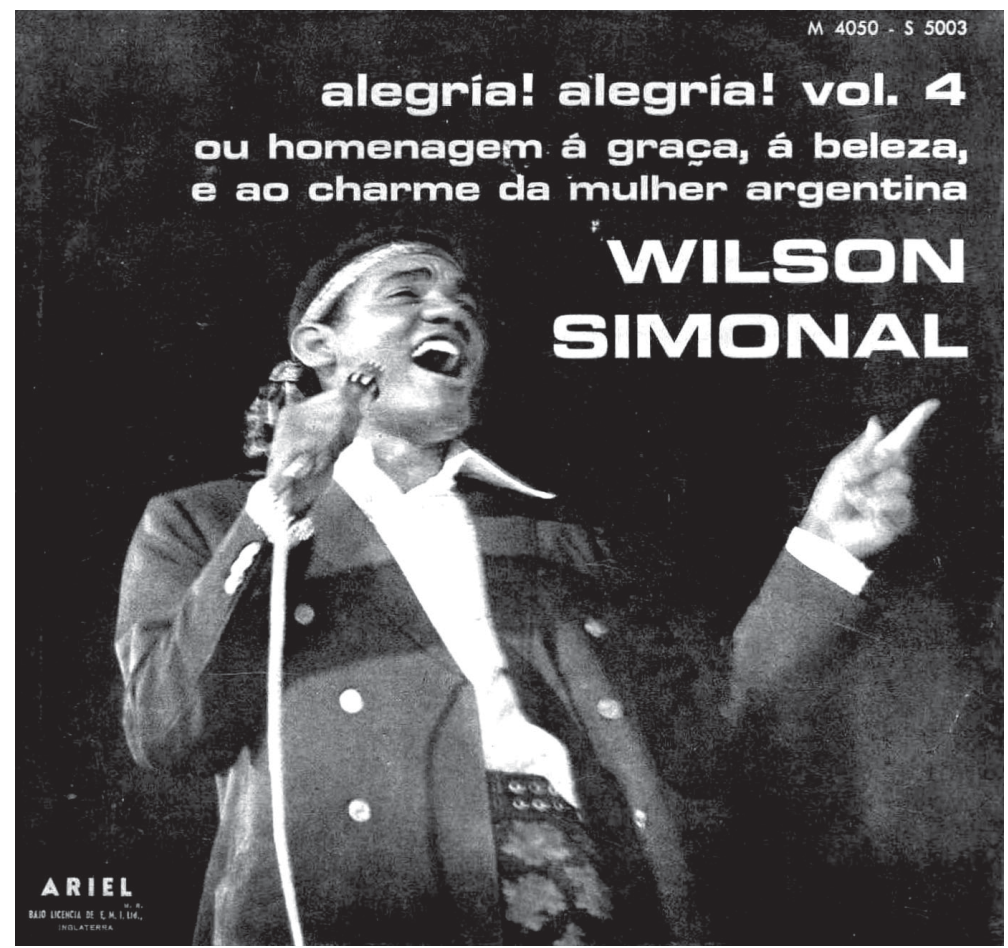

Figura 1

Alegria, Alegria de quatro volumes, Homenagem à graça, à beleza, ao charme e ao veneno da mulher brasileira (1969).

Não é paródia nem metáfora. Na voz de Simonal, a letra de País Tropical significa, não apenas aos desintelectualizados e aos ouvintes da indústria fonográfica, o esperado e o evidente:

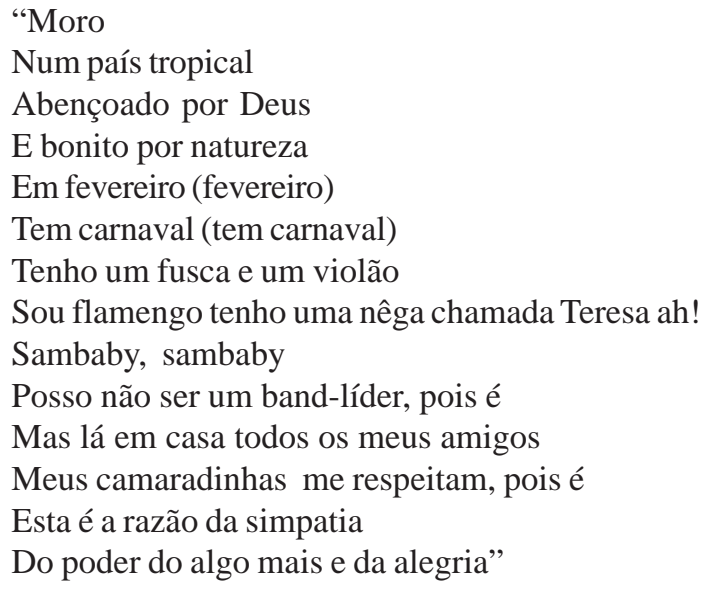


Além da imagem de Simonal (de alienado, de pró-ditadura e de ufanista), que cumpre importante papel significador da letra, existem elementos da linguagem musical que norteiam, ou que ao menos permeiam a intencionalidade, senão comercial, da louvação e da exaltação do Brasil e do brasileiro (temática de especial notoriedade e de massiva aceitação nacional em finados da década de 1960): o sentido da canção, muitas vezes, aparece de modo cifrado e quase sempre de maneira inconsciente nos ritmos, timbres, intensidades, melodias e harmonias (CONTIER, 1998).

Em sua versão, por exemplo, a canção se introduz e se desenvolve em um samba suavizado ${ }^{5}$ por notórias influências musicais latino-americanas, como os ritmos afro-cubanos da salsa e do cha-cha-cha ${ }^{6}$, comandados pelos timbres da percussão, pela melodia e acentos rítmicos do piano. Tal nuance se remete às paisagens caribenhas, que estão presentes no imaginário edênico e tropical brasileiro em associação à noção da beleza litorânea (praia, mar e sol) e ao dom dançante da nação. Promove-se uma conformidade entre o sentido mais direto da canção e o mais subjetivo, buscado no imaginário brasileiro, que direciona e reforça o entendimento semântico da letra. Estando isso atrelado, segundo os conceitos de Barthes (1990), ao sentido obtuso, que ao contrário do sentido óbvio, encontra-se fora da linguagem articulada (as línguas), mas que se faz presente no interior da interlocução.

Nas performances de País Tropical (1969), Sá Marina (1968) e Meu Limão, Meu Limoeiro (1967), com sua voz suave e aveludada, como a de um "abençoado por Deus" que canta sob a aparente ausência de esforço, na mais perfeita afinação e dicção, deixando transparecer "que sempre poderia ir bem mais longe do que vai" (BOSCO, 2009), Simonal, em sintonia com sua ascendente carreira, mitifica-se e torna-se símbolo de cantor provido de dom.

Dentro do contexto social brasileiro, o mito tem espaço especial, principalmente no que se diz respeito ao futebol, que, de acordo com DaMatta (1982), não é apenas um esporte de conotações próprias e específicas, é também um jogo a serviço de um conjunto de valores e relações sociais, no qual a população exercita e aprende costumes do que é ser brasileiro.

Nessa perspectiva, em que a construção sociocultural brasileira pode ser permeada e coadjuvada pelo futebol, e entendendo que no contexto futebolístico, a carreira dos jogadores se encontra fortemente condicionada aos estigmas do mito e do dom, pode-se inferir que a criação da imagem do cantor Simonal se forma de maneira paralela à dos grandes jogadores de futebol:

\footnotetext{
${ }^{5}$ Entender "suavizado" como o swing e balanço dançante da Turma da Pilantragem na maneira de fazer e tocar o arranjo das músicas.

${ }^{6}$ Ritmos esses que estiveram bastante presentes nos primeiros pequenos sucessos de Simonal e que tinham como compositor/arranjador Carlos Imperial. A exemplo a canção Terezinha (1961) (como mencionado no documentário Simonal - Ninguém sabe o duro que dei, dirigido por Calvito Leal, Cláudio Manoel e Micael Langer e lançado em DVD em 2008).
} 
tanto Simonal quanto os jogadores são "abençoados por Deus"; não necessitam fazer esforço pra cantar ou chutar a bola, nascem com o dom; e sempre podem surpreender o público com suas incalculáveis habilidades.

Essa relação e associação entre Simonal e futebol foram trabalhadas massivamente pelas campanhas publicitárias da Shell; na imprensa, uma foto na qual Simonal está vestido com a camisa da seleção brasileira junto a Pelé "vestido de Simonal" foi amplamente divulgada, sendo inclusive capa da revista Fatos e Fotos de Janeiro de 1970 (com destaque maior que a chamada da matéria sobre a morte de Costa e Silva) (Figura 2). A importância dessa elucubração se justifica no entendimento de que o futebol é, além de objeto de grande orgulho da nação (GIGLIO et al., 2008), um dos símbolos do Brasil Tropical. E quando se aponta um cerne comum entre a construção e associação da imagem de um jogador de futebol e a imagem do cantor Simonal, pretende-se localizá-lo (Simonal) dentro da identidade nacional tropical (já ocupada pelo futebol), na qual se permite, com autenticidade, discursar e cantar com a propriedade da verdade um ideário brasileiro, no caso o ufanista: a compatibilidade entre a voz de Simonal, mitificada e concebida como identidade nacional por vias de um aparente dom inato, presente na gravação de País Tropical, confere legitimidade ao discurso da canção.

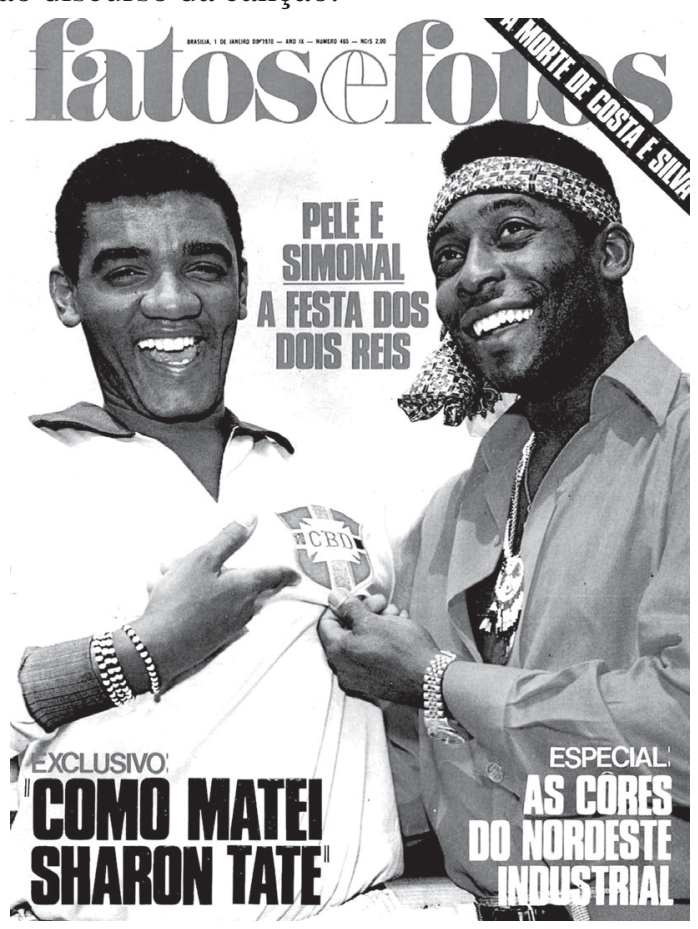

Figura 2

Capa da revista Fatos e Fotos de Janeiro de 1970 


\section{Hüüăases}

Adiciona-se a essa observação um contexto histórico de conturbação política e de mudança da percepção da questão social, no qual a identidade nacional é repensada e recriada pela emergência de novos heróis e mitos - ou seja, novos símbolos nacionais, divulgadores e representantes legítimos de uma identidade reconstruída (KERBER, 2008). O que confere, portanto, um espaço social e histórico à imagem de Simonal e às músicas que canta.

Ainda em meio à aura ufanista de Simonal, nota-se uma característica da letra que evidencia um traço inerente ao brasileiro e que corrobora e o vincula a uma identidade nacional, aflorando ainda mais, frente à população, a autenticidade do discurso ufanista da canção: a dificuldade de ser e pensar impessoalmente nos discursos e nas relações sociais, levando-as sempre para o lado afetivo, como observado por Holanda (1995) no seu ensaio sobre o "Homem Cordial". Sob a luz de Antonio Candido (1995):

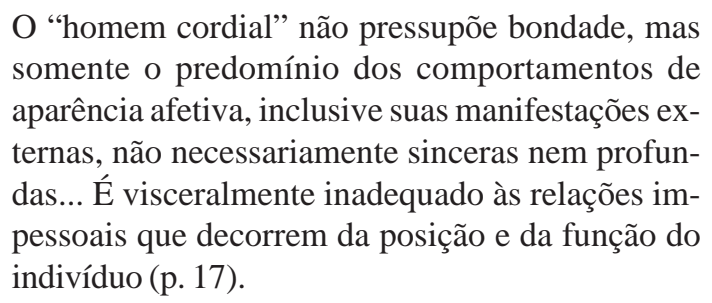

O texto da canção se constrói pelos elementos da relação de afeto com que o "eu" mantém com sua sociedade, que se encerra, portanto, nas relações pessoais, excluindo as relações impessoais, ligadas ao Estado e ao funcionalismo social. A partir dos relatos organiza-se uma sociedade forjada em três planos principais, do menos pessoal à particularização completa, aproximando o discurso ao plano utópico brasileiro engasgado pela "cordialidade", que estabelece identificação e aceitação popular da canção:

Meu país é tropical:
"Moro
Num país tropical
Abençoado por Deus
E bonito por natureza
Em fevereiro (fevereiro)
Tem carnaval (tem carnaval)"

Sou parecido com os outros:

"Tenho um fusca e um violão

Sou flamengo tenho uma nêga chamada Teresa ah!" 


\author{
Minha "cordialidade": \\ "Posso não ser um band-líder, pois é \\ Mas lá em casa todos os meus amigos \\ Meus camaradinhas me respeitam, pois é \\ Esta é a razão da simpatia \\ Do poder do algo mais e da alegria"
}

De acordo com Tatit (2002), ao analisar a letra da canção, a exaltação do Brasil poderia ocorrer de maneira genérica, todavia o compositor reduz o foco para a singularidade do brasileiro, que se materializa na voz do próprio enunciador. Interessante, então, notar a postura "cordial" de Simonal nas performances ao vivo: um artista que personifica o público, conversando e interagindo musicalmente durante toda a apresentação. De maneira semelhante a Roberto Carlos quando beija e entrega pessoalmente rosas às fãs. Simonal carrega, portanto, dentro da esfera interpretativa e performática o emblema "cordial" da nação.

Outro evento interpretativo protagonizado por Simonal, incorporado inclusive por Jorge Ben Jor, foi sucintamente analisado por Bosco (2009):

Na segunda vez em que a letra é cantada, Simonal suprime a última sílaba das palavras, dizendo só o suficiente para que se lhes entenda o sentido: "Mó num pá tropi/ abençoá por Dê/ e boni por naturê"... É um exagero, mas não absurdo, dizer que essa sílaba que falta é a distância que sempre nos faltou para passar de "gigante pela própria natureza" a “teu futuro espelha essa grandeza". Esse ufanismo incompleto, preguiçoso, é a graça em seu estado mais revelador.

Circunstância que fez com que Simonal ganhasse uma nova adjetivação: "Rei do Patropi". Pejorativa para os esquerdistas - já que o significado embutido na expressão País Tropical aproximava-se dos ideários ufanistas - e positiva à grande massa - uma justa e honrosa designação ao fabuloso cantor.

A partir de uma análise voltada aos aspectos da relação da melodia e das escolhas lingüísticas na canção e tendo em vista os conceitos de tematização e figurativização empregados por Tatit (2002) no livro "O Cancionista: composições de canções no Brasil", nós podemos levantar outros dois pontos que complementam o discurso ufanista.

A tematização consiste no emprego de segmentação e de ataques consonantais ao contorno melódico da canção, convertendo as tensões em impulsos somáticos fundados nos valores rítmicos da canção e na marcação dos acentos. 
Desenvolve-se no percurso da canção a compatibilidade entre tema de conteúdo (no texto) e tema de expressão (na rítmica da melodia). Tatit, a partir de suas análises sobre canções brasileiras, inferiu, não apensas por recorrência, que a tematização é propícia às construções de personagens, de valores-objetos e de valores universais, desempenhando um papel importante na materialização das idéias. Funcionando, portanto, como importante ferramenta na criação de uma canção que está vinculada a uma temática de exaltação de elementos nacionais.

Na primeira estrofe da canção (Figura 3), por exemplo, já se nota a segmentação da melodia e o emprego saliente das consoantes, em detrimento da utilização de prolongamentos melódicos em vogais, efeito aumentado pela interpretação de Simonal, que deixa bem claro os cortes silábicos (notável em toda a canção).

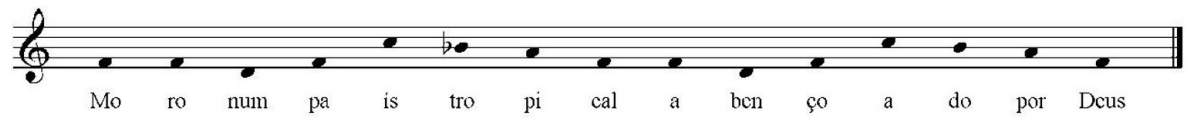

Figura 3

Primeira estrofe da canção

Tatit (2002) notou a utilização desse mesmo recurso (tematização e reforço interpretativo) em outras canções que centralizavam a temática da exaltação como, por exemplo, em Aquarela do Brasil (1939), Brasil Pandeiro (1963) e Samba da Minha Terra (1957).

A figuratização, por outro lado, consiste no emprego da fala coloquial no contexto melódico e lingüístico da canção, ou seja, a voz que fala permeia a voz que canta. No âmbito melódico verifica-se a ramificação tonêmica, na qual a melodia se assemelha aos processos de ascendência, descendência e suspensão entoativas da fala. Dessa maneira, de acordo com Tatit (2002), os tonemas ascendentes e suspensivos sugerem continuidade, complemento ou resposta; os descendentes sugerem repouso, afirmação e conclusão. No âmbito lingüístico, verifica-se o emprego de dêiticos vocativos, imperativos, demonstrativos, gestuais, exclamativos, interjetivos ou compostos por expressões e gírias. De maneira geral a figuratização confere credibilidade à mensagem do cancionista e naturalidade ao texto, aproximando a situação da letra a uma realidade possível da vida cotidiana.

No trecho abaixo (Figura 4) nota-se o emprego, tanto dos dêiticos (como "pois é") quanto dos tonemas (tessitura próxima a da fala cotidiana e a descendência melódica dando valor conclusivo ao final da frase), que mesclados à malandragem e à pilantragem de Simonal ganham força: 


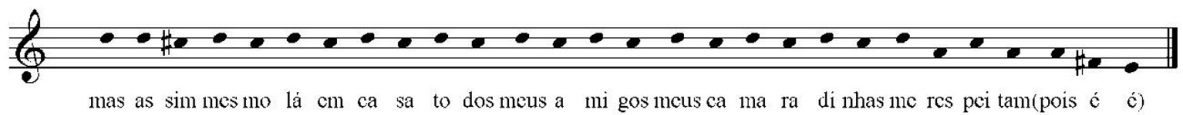

Figura 4

Nota-se o emprego, tanto dos dêiticos quanto dos tonemas

Recursos esses, que segundo Tatit (2002), fazem-se presentes em toda obra de Jorge Ben Jor.

\section{A desinvenção Tropicalista}

Como pontua Lontra (2000), os críticos, apesar das divergências naturais, são unânimes em afirmar que o Tropicalismo atualiza os contrastes nacionais por intermédio de um discurso que evidencia os paradoxos históricos do país. E que, aos olhos de Schwarz (1978), ao chocar o arcaico com o moderno, tendeu a estabelecer uma visão estática, atemporal e insuperável das contradições da realidade social, econômica e cultural - traduzidas principalmente, após 1964, nas manifestações mais avançadas da integração imperialista internacional e da ideologia burguesa mais antiga -, construindo uma imagem do absurdo que resulta em uma alegoria do Brasil, em um procedimento, segundo Favaretto (2000), ligado à linha da modernidade, que consiste em redescobrir e criticar a tradição a partir da experiência cosmopolita dos processos artísticos. E que, com o entendimento das contribuições fundamentais das vanguardas e em acordo com o ideário do Modernismo, se perfaz parcialmente em função dos parâmetros da reformulação da linguagem e do nacionalismo crítico (CYNTRÃO \& CHAVES, 1999) - sem se esquecer de questionar "a dialética histórica e seus propósitos de arte orientada para mensagem" (PERRONE, 1988; p. 77).

Em comparação a outras tendências musicais notáveis da década de 1960, como a Canção de Protesto e a Jovem Guarda, a Tropicália, ao realizar uma mistura de elementos da indústria cultural e de materiais da tradição brasileira, deslocou o debate dicotômico existente de arte engajada e arte alienada. Reformulando as discussões culturais, o Tropicalismo repensou as relações entre arte e política, em um movimento que permitia com que o Brasil fosse visto com novos olhos (FAVARETTO, 2000).

Dentre os recursos utilizados na construção do discurso Tropicalista, dos quais se podem extrair ferramentas de análise de canção, os mais recorrentes, de acordo com o levantamento da bibliografia crítica feito por Lontra (2000), são: 
Paródia. Que se manifesta tanto no nível intertextual quanto no sonoro, ressaltando o ridículo ao retirar um texto de seu uso habitual e colocando-o em outro contexto, por meio da imitação de obra ou de procedimento referente a alguma corrente artística;

Enumeração Caótica. Conjunto de termos díspares colocados sob aparente ilogicidade em um mesmo contexto, e que ocorrem, no contexto tropicalista, principalmente nos níveis de justaposição de sons/sílabas, de palavras, de versos/frases, de estrofes/ritmos e de composições heterogêneas;

Antítese e Paradoxo. Figuras pelas quais se opõem duas palavras ou dois pensamentos de sentido contrário, para que com eles se consigam revelar as forças caóticas em conflito;

Antimetáfora. Recurso, construído pela substituição do desdobramento natural do sentido ideológico pelo inesperado, pelo qual se estabelece o absurdo e a impressão surrealista;

Uso Simbólico de Horror Realístico. Utilização de símbolos que remetem a uma forte impressão realística de repulsa ou desagrado, pelos quais se percebe o mundo espedaçado, fragmentado e em descontinuidade;

Linguagem da Fresta. Utilização de interrupções do pensamento, utilização de reticências e exclamações entre frases e palavras, deixando suspensas idéias e interrogações, empregando metonímias e sinonímias;

Alegoria. Recurso pelo qual as imagens tropicalistas ganham maior sentido - sem apagar o contraditório e sem privilegiar verdades -, no qual, segundo Walter Benjamin, é: "o processo construtivo fundado na linguagem em que perdura uma distância entre a representação e a intenção significativa; é um figurar essencialmente polissêmico, ambivalente, estranho àquela direta identificação de sujeito e objeto que caracteriza a consciência do símbolo" (apud LONTRA, 2000; p. 51).

Esses recursos, que compõem um aspecto do procedimento estético, permitem a desconstrução do discurso ufanista ao ponto em que no Tropicalismo, segundo Favaretto (2000) e Villaça (2004), os arranjos e as escolhas musicais envolvidas na produção da canção não serviam simplesmente de acompanhamento ou de reforço da mensagem da letra, (como ocorria, por exemplo, na Canção de Protesto), pelo contrário, trabalhavam muitas vezes de maneira destoante e contrastante com a letra, trazendo ambigüidades e cifrando sentidos. Em um percurso que fez com que os critérios de apreciação da canção fossem reformulados, já que o enfoque da crítica literária sedia lugar para uma linguagem da canção que não se encerrava na letra, ou seja, que rompia o paradigma que separava a letra da música, em um movimento que trazia autonomia à canção enquanto linguagem una e coesa.

Tendo consciência (1) da complexa formação literária dos integrantes da Tropicália que incluiu Drummond, João Cabral, Guimarães Rosa, Clarice Lispector, 
Oswald de Andrade e poesia concreta, (2) da extensa vivência musical da qual fizeram parte os ritmos regionais, as manifestações folclóricas e a música urbana, Beatles, Bob Dylan, Jazz e Bossa Nova e (3) do conhecimento sobre cinema, teatro e artes plásticas (Favaretto, 2000) e ainda, como destacou Riserio (1994), (4) do importantíssimo contato que tiveram com pesquisadores e artistas estrangeiros como Koellreutter, Pierre Verger e Yanka Rudzka na Universidade da Bahia, pretende-se, excluindo-se as hipóteses ingênuas e reconhecendo as influências que tiveram na formação da mentalidade e na sensibilidade artístico-cultural (que muitas vezes transparece nas canções), elucidar pontos que evidenciem como o discurso ufanista associado à versão de País Tropical - canção que possui por essência, como aqui defendido, um caráter mimético representativo na letra -, interpretada por Wilson Simonal, é desconstruído e reinventado pelos Tropicalistas.

A gravação de referência, que conta com a participação de Caetano Veloso e Gilberto Gil, está em um dos álbuns que compõem a discografia básica do movimento de acordo com Calado (1997): o segundo disco individual de Gal Costa, gravado em 1969, com o selo da Philips (Figura 5), que contem músicas referenciais como Cinema Olympia (composta por Caetano) e Cultura e Civilização (composta por Gil).

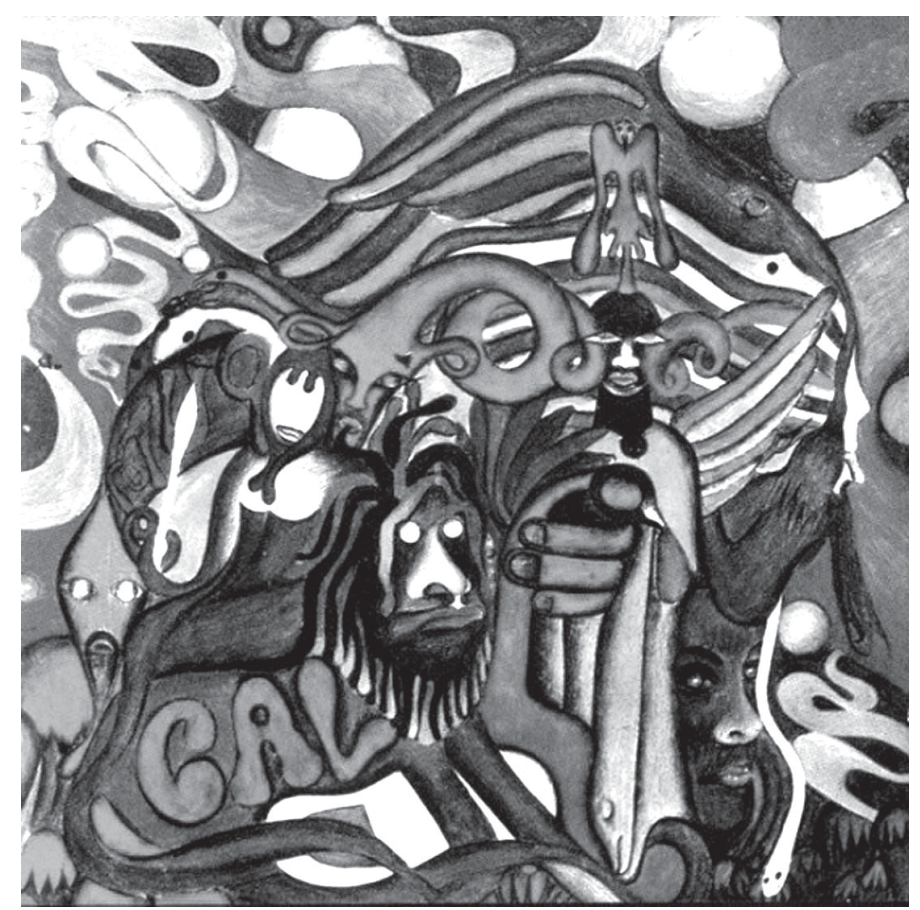

Figura 5

Disco individual de Gal Costa, gravado em 1969, com o selo da Philips 
Nota-se na gravação um constante deboche e sarcasmo à exaltação do país tropical nas entrelinhas da "linguagem de fresta". Entre os versos (na segunda vez que as primeiras estrofes são repetidas) "Moro" e "Num país tropical", se faz presente uma risada (rá!) $\left(1{ }^{\prime} 11 \text { ” }\right)^{7}$, que põe em questão o orgulho de morar no país tropical. Nesse trecho, o desleixo e a avacalhação na entoação vocal do verso "Num país tropical", em especial na palavra "tropical" (1'14"), protagonizado pela voz de Caetano Veloso, em contraposição a euforia do "Moro" (1'10"), incita, sarcasticamente, a sensação decepcionante de morar nesse país, em tom de deboche à exaltação e ao orgulho tropical. Esse mesmo processo de avacalhação com intuito de deboche é usado outras vezes na canção, como no backing vocal do verso "Tem Carnaval" (1'26), remetendo-se, agora, em tom de chacota o orgulho da nação representado pela festa mais popular do Brasil. No verso "Abençoado por Deus" (1'16") a risada retorna, desconstruindo e questionando, desta vez, a áurea de monumento sagrado na qual o país constrói, por decreto divino, sua perfeição.

Nesse contexto, o riso, a zombaria, a ironia e o grotesco não são meros efeitos, alcançam eficácia crítica, que nesse caso específico, desconstrói a ideologia nacional-ufanista, oferecendo uma imagem alienada do Brasil e, simultaneamente, um espetáculo de suas indeterminações (FAVARETTO, 2000).

Em um trecho da música (0'50") escuta-se um "Bi-Bi", protagonizado por Gilberto Gil, em alusão à buzina de um carro, no caso o "fusca" (0'46"): "Tenho um fusca e um violão/Sou flamengo tenho uma nêga chamada Teresa! Bi-Bi". Interessante notar que a retomada do "carro" vem em seguida do "nêga chamada Teresa!". Se lembrarmos da letra da canção Calhambeque (que também usa o "Bi-Bi" em referência ao carro) de Roberto Carlos na Jovem Guarda, notaremos que o carro é um objeto de consumo utilizado para conquistar garotas atraentes. Esse consumismo que era criticado pela esquerda não é depreciado na canção, pelo contrário, é justificado: na seqüência desse trecho (que não se faz presente na versão de Simonal), após o verso "Mas assim mesmo e contente/Eu não devo nada a ninguém" (0'59"), Caetano, ao fundo, dialoga com a letra dizendo "Ah! Justamente" (1'03"), ou seja, se se está contente e não se deve nada a ninguém, se pode fazer o que quiser, mesmo se for a prática desse consumismo criticado. De maneira irônica ou não, é exposta na canção a ligação de se ter um carro e conquistar uma garota, e isso era fruto de uma idéia que remetia aos filmes hollywoodianos e às publicidades consumistas dos anos 60, que reiteradamente expunham tal situação e que eram recebidas no Brasil de maneira massiva. O entendimento disso nos faz chegar

\footnotetext{
${ }^{7}$ As referências ao minuto e segundo no qual acontece na gravação o analisado são sempre aproximadas e indicam sempre um início, não um intervalo de tempo.

${ }^{8}$ Alguns trechos: "O Calhambeque, bi-bi/Buzinei assim o /Calhambeque Bi Bidhu! Bidhubidhu Bidubi!... E logo uma garota/Fez sinal para eu parar... E muitos outros brotos/Que encontrei pelo caminho/ Falavam: "Que estouro/Que beleza de carrinho"
} 
a uma contradição direta entre o ufanismo, caracterizado pela importância/ orgulho do fusca (um carro carregado de brasilidade), e a cultura importada do consumismo (relação entre o carro e a "nêga" conquistada): paira no ar a interrogação: onde está o sentido em separar o importado e o nacional de maneira dicotômica no plano político e ideológico se a sociedade já absorveu uma cultura que permeia e se confunde em influências e em símbolos? Pode-se entender isso como uma crítica à esquerda, ou de maneira irônica, uma crítica ao ufanismo cego de suas contradições.

Pode-se notar na canção o emprego, ou ao menos alusão, de elementos musicais advindos da cultura norte-americana, que entram em choque com o contexto esperado por uma letra de conteúdo ufanista. Como se pode perceber, por exemplo, nos backings vocals ao estilo das produções de Rock iê-iê-iê dos anos 60 (Eeee!, Aaaa!) presentes ao longo dos versos "Sambaby, sambaby/Posso não ser um band-líder" (1'34"), "Mas meus amigos, todos eles" (1'40") e "Esta é a razão da simpatia" (1'46"). Vale notar também, na voz de Gilberto Gil, a alusão, nas intermitências desses seguimentos, ao naipe de metais de uma big band de jazz. (alusão à Harmonia em Bloco, uma ferramenta extremamente utilizada nos arranjos desse tipo de formação musical norte-americano entre os "respiros" da melodia principal ou mesmo em sua própria condução) interpretação que ganha reforço na expressão "band-líder" (1'36") empregada na letra, uma referência aos líderes desses grandes grupos.

Dentro dessa áurea norte-americana, nota-se também a influência de uma linguagem guitarrística, advinda do Rock, do Jazz e do Blues, empregada no violão, um instrumento permeado na tradição musical brasileira em contraposição a guitarra elétrica, até então fortemente associada à cultura norte-americana9 . A observação se faz evidente ao fim da última repetição da canção, em meio às superposições vocais, com o uso excessivo da escala pentatônica blues ${ }^{10}$, embora já se note tal característica no começo da música, que é introduzida por uma nítida frase de violão que se utiliza da referida escala (Figura 6).

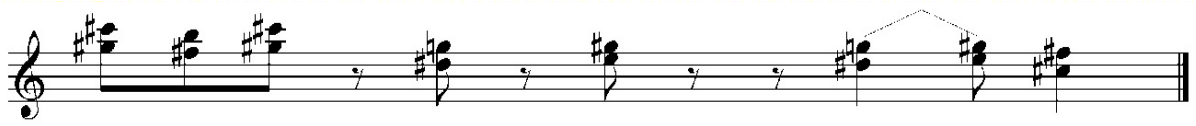

\section{Figura 6}

Frase de violão que se utiliza da referida escala pentatônica blues

${ }_{9} \mathrm{O}$ violão e a guitarra elétrica chegaram a ser símbolos da dicotomia e bipolarização política e ideológica brasileira: o primeiro, autêntico instrumento brasileiro presente na cultura, e o segundo, que se inseria culturalmente como fruto da importação cultural e do imperialismo norte-americano. De um lado a arte engajada e de outro a alienada.

${ }^{10}$ Essa escala é construída pela seguinte relação intervalar: fundamental, terça menor, quarta justa, quinta diminuta, quinta justa e sétima menor. Tradicionalmente, foi uma escala extremamente utilizada no Jazz, no Blues e, posteriormente no Rock britânico e americano, caracterizada pela utilização da quinta diminuta como nota de passagem (não havia repouso sem intenção nela), servia de ligação entre outras duas notas. 
As notas utilizadas são: Dó sustenido (fundamental), Mi (terça menor), Fá sustenido (quarta justa), Sol (quinta diminuta), Sol sustenido (quinta justa), $\mathrm{Si}$ (sétima menor). Todas essas pertencentes à escala. A única nota que é empregada e não faz parte dela é o Ré sustenido, mas que não descaracteriza a pentatônica blues, já que tem menos destaque que a nota com a qual soa junto (Sol) e aparece de maneira rápida, de passagem, apenas como aproximação da nota Mi. Vale notar que influência semelhante transparece também na condução das linhas melódicas do contra-baixo elétrico.

Essas ambigüidades, reveladoras de uma antropofagia cultural ${ }^{11}$, constroem uma relação entre estética e crítica social, em que esta última se desloca, parcialmente, do tema para os processos e os elementos construtivos da canção. Frente ao clima de bipolarização ideológica e cultural, centrado nas raízes nacionais e na importação cultural, o caráter ufanista e nacionalista da canção é parodiado, ou minimamente questionado, escancarando-se elementos que não se encaixam no mesmo discurso, a não ser numa ótica nacional absurda para o momento ou alegórica, adversa da daquele ufanismo pregado pós-68 e da intelligentsia esquerdista.

Nos princípios da gravação (0'09") e nos finados (2'16") nota-se a justaposição de sons, sílabas, palavras, frases, ritmos e timbres que é melhor definida pelo processo de "enumeração caótica", que na perspectiva futurista se encaixa numa liberdade de uso de elementos, e que pela sensação de simultaneidade de informação ajudaria a atingir uma visão diversificada e contraditória de uma mesma imagem. Ou seja, todo elemento é posto de maneira ilógica, sem submissão semântica, escancarando as ambigüidades e os paradoxos da construção estética, que em tempos de extrema dicotomia (arte engajada e alienada, esquerda e direita, nacional e internacional) se configura em uma crítica à visão bipolarizada do Brasil, e que se perfaz na construção de um olhar que não privilegia verdades e nem nega contradições, e que por consequiência não alude a um Brasil ufanista, a não ser de maneira alegórica.

\section{Breves considerações}

Acredita-se que os elementos essenciais da desconstrução do discurso ufanista, encontrado em associação a interpretação de Wilson Simonal ou apreendido do sentido mais direto da letra, e da reinvenção do sentido, que se projetam em uma

\footnotetext{
${ }^{11}$ Dilmar Andrade esclarece bem a idéia de antropofagia cultural que permeou o tropicalismo no seguinte trecho: "Operando um descentramento cultural e valorativo multiperspectivista, pela articulação de múltiplas falas e olhares, contrário aos discursos que antes tomavam univocamente a realidade nacional, e pelo aproveitamento das manifestações estéticas de várias proveniências, a Tropicália configura um novo material, uma 'obra aberta' de múltiplas significações. As contradições de uma 'contemporaneidade não coetânea' não são objeto de mera denúncia, mas suas ambigüidades ou ambivalências são incorporadas na obra, na nova forma artística". (MIRANDA, D. Carnavalização e multidentidade cultural: antropofagia e tropicalismo. Tempo Social; Rev. Sociol. USP, S.Paulo, 9(2): 125-154, outubro de 1997)
} 
desinvenção do estabelecido, estejam expostos sinteticamente acima. Sobretudo em um trajeto moldado pela ressignificação que ultrapassa os limites das nuances interpretativas da letra.

A obra de arte, como a considera Umberto Eco (1969), traz consigo, de maneira inerente, a possibilidade de múltiplas leituras, ou ainda, como aponta Joly (1996) quando trata daquilo que é visual, é polissêmica. Todavia o que notamos com a análise não é apenas a capacidade que a letra dessa canção tem de se mostrar passível de diferentes interpretações; é, sobretudo, a autenticidade com a qual ela é incorporada por ambos os discursos, consideravelmente antagônicos, construindo um todo uno e coeso em cada caso, com extrema força mimética.

Cabe pontuar que não se trata apenas, como acontece com qualquer objeto de análise, da variabilidade de significados que as coisas recebem devido ao contexto da emissão, da recepção e do canal, mas também da capacidade saliente que a letra, entendida como parte constitutiva da canção, tem de ser transformada para os (e não somente pelos) diferentes contextos.

\section{Referências bibliográficas}

BARTHES, R. O óbvio e o obtuso: ensaios críticos III. Trad. Léo Novaes. Rio de Janeiro: Nova Fronteira, 1990.

BOSCO, F. Mó num pá tropi: a graça e a desgraça de Wilson Simonal. Revista Cult., 138, 2009.

CALADO, C. Tropicália: a história de uma revolução musical. São Paulo: Editora 34, 1997.

CALDAS, W. A cultura político-musical brasileira. São Paulo. Musa, 2005.

CANDIDO, A. O significado de Raízes do Brasil. In: S.B. de HOLANDA. Raízes do Brasil. $26^{\mathrm{a}}$ Edição. Pp. 9-21. São Paulo: Companhia das Letras, 1995.

CONTIER, A.D. Edu Lobo e Caros Lyra: o nacional e o popular na canção de protesto. Revista Brasileira de História, 18(35): 13-52, 1998.

CYNTRÃO, S.H. \& CHAVES, X. Da Paulicéia à Centopéia Desvairada. As Vanguardas e a MPB. Rio de Janeiro. Editora ELO, 1999.

DAMATTA, R. (Org.). Esporte na sociedade: um ensaio sobre o futebol brasileiro. In: Universo do futebol: esporte e sociedade brasileira. Pp. 19-42. Rio de Janeiro: Editora Pinakotheke, 1982. 
ECO, U. Obra aberta: forma e indeterminação nas poéticas contemporâneas. São Paulo: Editora Perspectiva, 1969.

FAVARETTO, C.F. Tropicália: alegoria, alegria. Ateliê Editorial, 2000.

FERREIRA, G.A.A. Quem não tem swing morre com a boca cheia de formiga: Wilson Simonal e os limites de uma memória tropical. Dissertação de Mestrado em História. Niterói: Universidade Federal Fluminense, 2007.

GIGLIO, S.S.; MORATO, M.P.; STUCCHI, S. \& ALMEIDA, J.J.G. O dom de jogar bola. Horizontes Antropológicos, 14 (30): 67-84, 2008.

HOLANDA, S.B. Raízes do Brasil. 26ª Edição. São Paulo: Companhia das Letras, 1995.

JOLY, M. Introdução à análise da imagem.Campinas: Editora Papirus, 1996.

KERBER, A. Nacionalismo e ufanismo na Argentina e no Brasil dos anos 1920 e 1930 através da trajetória artística de Carlos Gardel e Carmen Miranda. História - Unisinos, 12 (3): 271-284, 2008.

LONTRA, H.O.H. Tropicalismo: a explosão e seus estilhaços. In: S.H. CYNTRÃO (Org.). A Forma da Festa. Brasília: Editora da UnB, 2000.

LOPES, P.E. A desinvenção do som: leituras dialógicas do tropicalismo. Campinas: Editora Pontes, 1999.

MOTTA, N. Noites Tropicais: solos, improvisos e memórias musicais. Rio de Janeiro. Editora Objetiva, 2000.

NAPOLITANO, M. Cultura Brasileira: utopia e massificação (1950-1980). São Paulo. Editora Contexto, 2001.

NASCIMENTO, A.D. "Para animar a festa" A música de Jorge Ben Jor. Dissertação de Mestrado em Música. Campinas: Universidade Estadual de Campinas, 2005.

PERRONE, C.A. Letras e letras da MPB. Rio de Janeiro: Editora ELO, 1988. PINHEIRO, A. Simonal, em si... maior. Revista Raça Brasil, Edição 133, 6 de Julho de 2009.

RISERIO, A. Avant-garde na Bahia. São Paulo. Instituto Lina e Pietro Maria Bardi, 1994.

TATIT, L.A.M. O cancionista: composição de canções no Brasil. São Paulo. Editora da Universidade de São Paulo, 2002. 
VELOSO, C. Verdade Tropical. São Paulo. Companhia das Letras, 1997.

VILLAÇA, M.M. País Tropical: experimentalismo e engajamento na música popular (Brasil e Cuba, 1967 - 1972). São Paulo. Editora Humanitas/FFLCH/ USP, 2004.

SCHWARZ, R. Cultura e Política, 1964-1969. In: O pai de família e outros estudos. São Paulo: Editora Paz e Terra, 1978.

\section{Discografia}

BEN JOR, J. País Tropical. Intérprete: Wilson Simonal. In: W. SIMONAL Alegria! Alegria!, Volume 4 - Homenagem à graça, à beleza, ao charme e ao veneno da mulher brasileira. Odeon/EMI, 1969. LP estéreo.

BEN JOR, J. País Tropical. Intérpretes: Gal Costa, Caetano Veloso e Gilberto Gil. In: G. COSTA. CBD-Philips, 1969. LP estéreo.

\section{Filmografia}

“SIMONAL - ninguém sabe o duro que dei”. Direção de Calvito Leal, Cláudio Manoel e Micael Langer. Brasil, 2008. DVD (86 min.). 